\title{
Rheumatoid Arthritis Disease Activity Index-5: an easy and effective way of monitoring patients with rheumatoid arthritis Vikram S. Tanwar ${ }^{\mathrm{a}}$, Harpreet Singh ${ }^{\mathrm{b}}$, Anjali Saini ${ }^{\mathrm{a}}$, Gagandeep Sukhija ${ }^{\mathrm{b}}$, Sameer Arora ${ }^{\mathrm{b}}$, Ankit Kalra ${ }^{\mathrm{b}}$
}

aDepartment of Medicine, SHKM GMC, Nalhar, ${ }^{b}$ Department of Medicine, PGIMS, Rohtak, Haryana, India

Correspondence to Vikram S. Tanwar, MD Department of Medicine, SHKM GMC, Nalhar, Haryana 122107, India. Tel: 01267-203734; e-mail: drvikrampgi@gmail.com

Received 14 February 2019 Accepted 19 June 2019

Egyptian Rheumatology \& Rehabilitation 2019, 46:269-277

\begin{abstract}
Objective
To study the utility of the Rheumatoid Arthritis Disease Activity Index-5 (RADAI-5) as a valid tool for daily rheumatoid arthritis (RA) monitoring and to compare its predictability to assess RA activity with respect to Disease Activity Score 28 (DAS28) and Clinical Disease Activity Index (CDAI).
\end{abstract}

Patients and methods

A total of 100 patients with RA (diagnosed as per American College of Rheumatology 1987 criteria) were enrolled in the study group. Each patient was assessed two times with 3-month interval for disease activity (DA) using DAS28, CDAI, and RADAI-5. Spearman's correlation coefficient $(\rho)$ for correlation and kappa for agreement between different activity measures were assessed.

Results

In our study group, $19 \%$ patients were men and $81 \%$ patients were women, with male to female ratio of $1: 4.3$. Their mean age was $44.4 \pm 11.8$ years, and their mean disease duration was $67.5 \pm 59.8$ months. On initial visit, that is, baseline, mean DA as per RADAI-5, DAS28, and CDAI were $5.14 \pm 2.17,5.58 \pm 1.55$, and $27.96 \pm 15.46$, respectively, and on follow-up visit, the readings were $3.76 \pm 1.92,4.54 \pm 1.41$, and $17.67 \pm 12.46$, respectively. The mean changes in DA at follow-up visit were -1.37 \pm 2.15 by RADAI- $5,-1.04 \pm 1.58$ by DAS 28 , and $-10.29 \pm 15.75$ by CDAI. Changes in DA indices correlated significantly with each other with $\rho$ ranging from 0.8 to 0.9 $(P<0.001)$. An average agreement was found among all three measures at different DA level.

\section{Conclusion}

RADAl-5 seems to be an effective tool with high tendency to assess the changes in RA DA in routine patient care in hospital settings as well as in home-based settings.

Keywords:

Clinical Disease Activity Index, Disease Activity Score 28, Rheumatoid Arthritis Disease Activity Index-5

Egypt Rheumatol Rehabil 46:269-277

(C) 2019 Egyptian Society for Rheumatology and Rehabilitation $1110-161 \mathrm{X}$

\section{Introduction}

Rheumatoid arthritis (RA) is a chronic systemic inflammatory disease characterized by persistent synovitis of diarthrodial joints often symmetrical in distribution, resulting in pain, stiffness, and loss of function [1]. Apart from joint involvement, a wide variety of extra-articular features like rheumatoid nodules, vasculitis, lymphadenopathy, serositis, neuropathies, episcleritis, anemia, and amyloidosis may also develop [2]. Management of RA often involves repetitive assessment of disease activity (DA) by using activity measures and initiation of disease modifying anti-rheumatic drugs [3]. Several widely used indices [Disease Activity Score (DAS28) and Clinical Disease Activity Index (CDAI)] and activity measures like number of swollen joint count (SJC) and tender joint count (TJC) requires physician's intervention (to perform joint counts), and hence, cannot be used by patient himself/herself at homebased settings. Most practicing rheumatologists either do not have sufficient time to perform joint counts at every patient visit or they do not measure them otherwise $[4,5]$, which is a prerequisite for the calculation of the respective indexes. However, data from patients only can be as useful as any other information to assess and monitor the disease [6]. It has been seen that for prognosis and monitoring the disease, patient questionnaire's score for functional status appeared to be equally or even more informative than even a full joint count [7]. Rheumatoid Arthritis Disease Activity Index-5 (RADAI-5), a newly developed activity assessment tool, has been evaluated in various studies for DA, and it relies on patient-reported outcomes only [8-11]. We performed an observational and follow-up study to

This is an open access journal, and articles are distributed under the terms of the Creative Commons Attribution-NonCommercial-ShareAlike 4.0 License, which allows others to remix, tweak, and build upon the work non-commercially, as long as appropriate credit is given and the new creations are licensed under the identical terms. 
evaluate its effectiveness in monitoring the RA DA and to compare its utility with the well-known DA measures (i.e. DAS28 and CDAI).

\section{Patients and methods} Patients and data collection

This prospective and observational study was conducted at Rheumatology outdoor of our institute. The ethical committee of the institution approved the study, and a written informed consent was obtained from each patient before enrollment in the study. A total of 100 patients with RA, diagnosed as per American College of Rheumatology 1987 revised criteria [12], were enrolled as patients in the study. Those patients who were experiencing hypothyroidism, severe anemia, and renal, cardiac, liver, or pulmonary disease were excluded from the study group because all these can affect the nonspecific symptoms of RA, and second, they may alter the patient's perception of general health as well as acute-phase reactants [erythrocyte sedimentation rate (ESR) and C-reactive protein)]. All patients were assessed two times during the study (first assessment was done at the time of enrollment and second assessment was done at 3-month follow-up visit). Each patient was first assessed for core data set measures, that is, TJC and SJC, patient's global health assessment [patient's global assessment (PGA) or general health), and evaluator's global health assessment (EGA) as per visual analog score (VAS) scale, as well as acute-phase reactant - ESR, and then the DA measures (DAS28 and CDAI) were assessed by using these core data set measures. All patients were asked to complete the RADAI-5 questionnaire (Table 1 ) at the same visit. Total RADAI-5 score is calculated as a mean of nonmissing items, which ranges from 0 to 10 [8].

Table 1 Rheumatoid Arthritis Disease Activity Index-5 questionnaire [8]

\begin{tabular}{lc}
\hline RADAI-5 items & $\begin{array}{c}\text { Possible } \\
\text { range }\end{array}$ \\
\hline $\begin{array}{l}\text { 1. How active was your arthritis in general during } \\
\text { the past } 6 \text { months? }\end{array}$ & $0-10$ \\
2. How active is your arthritis today in terms of \\
pressure sensitivity and swelling of the joints? & $0-10$ \\
3. How severe is your arthritis pain today? & $0-10$ \\
4. How would you describe your general health? & $0-10$ \\
5. Were your joints stiff when you woke up today? & $0-10$ \\
If so, how long did this stiffness last? & \\
Total RADAl-5 score & $0-10$ \\
\hline
\end{tabular}

RADAI-5, Rheumatoid Arthritis Disease Activity Index-5. Adapted with permission from Leeb Burkhard.
DAS28 was calculated by using following formula [13]: $\begin{aligned} \mathrm{DAS} 28 & =0.56 \sqrt{ } \mathrm{TJC}+0.28 \sqrt{ } \mathrm{SJC}+0.70(\log \mathrm{ESR}) \\ & +0.014(\mathrm{GH}) .\end{aligned}$

where TJC=tender joint count (0-28).

SJC=swollen joint count $(0-28)$.

$\mathrm{ESR}=$ erythrocyte sedimentation rate.

$\mathrm{GH}=$ global health on VAS $(0-100 \mathrm{~mm})$.

CDAI was calculated by using following formula [14]:

$\mathrm{CDAI}=\mathrm{TJC}+\mathrm{SJC}+\mathrm{PGA}+\mathrm{EGA}$

where

TJC $=$ tender joint counts $(0-28)$.

$\mathrm{SJC}=$ swollen joint counts (0-28).

PGA=patient's global assessment of DA (as per VAS scale: $0-10 \mathrm{~cm}$ ).

EGA=evaluator's global assessment of DA (as per VAS scale: $0-10 \mathrm{~cm}$ ).

\section{Statistical analysis}

The statistical analysis was performed using Statistical Package for Social Sciences (version 20; SPSS, Chicago, Illinois, USA). Descriptive statistics were done by number and percentage as well as mean and SD. Correlations were calculated using Spearman's correlation coefficient $(\rho)$, which ranges from -1 to +1 ; a positive value indicates a proportional relationship between the two variables, a value of 1 indicates a perfect correlation, a value of 0 indicates no correlation, and a negative value indicates an inversely proportional relationship between the two variables [9]. The level of statistical significance was set at a $P$ value less than 0.05 . The study group was categorized into four groups as per the level of DA. The various categories of disease severity according to the various scales were defined as follows: remission like state: $0.0<\mathrm{RADAI}-5 \leq 1.4, \quad 0.0<\mathrm{DAS} 28 \leq 2.6$, and $0.0<$ CDAI $0-2.8$; mild: $1.6 \leq \mathrm{RADAI}-5 \leq 3.0$, $2.6<\mathrm{DAS} 28 \leq 3.2$, and $2.8<\mathrm{CDAI} \leq 10.0$; moderate: $3.2 \leq \mathrm{RADAI}-5 \leq 5.4, \quad 3.2<\mathrm{DAS} 28 \leq 5.1, \quad$ and $10<\mathrm{CDAI} \leq 22.0$; and severe: $5.6 \leq \mathrm{RADAI}-5 \leq 10.0$, $5.1<\mathrm{DAS} 28 \leq 9.4$, and $22.0<\mathrm{CDAI} \leq 76.0$ [13-16]. All patients were then distributed into aforementioned categories and cross-tabulation was done, and kappa statistics was applied for agreement 
analysis between RADAI-5 and composite indices. Kappa values define the following categories of agreement: less than $0.20=$ poor; $0.21-0.40=$ fair; $0.41-0.60=$ average; $0.61-0.80=$ good, and more than or equal to $0.81=$ very good [9].

\section{Results}

A total of 100 patients with RA were included in the present study. Their mean age was $44.4 \pm 11.8$ years, and their mean disease duration was $67.5 \pm 59.8$ months. In the study group, 19 (19\%) were men and $81(81 \%)$ were women, with male to female ratio of $1: 4.3$. Rheumatoid factor (RF) positivity in the study group was $76 \%$. Values for the core data set measures and DA indices are given as means and are shown in Table 2. Distribution of patients according to the activity level (individual tool wise assessment) is shown in Table 3 (Figs 1,2). The correlation of RADAI-5 with various activity parameters at both visits is shown in Table 4.

At both the assessments, RADAI-5 was found to be correlated significantly with DAS28-ESR, CDAI, and core data set measures (all $\rho>0.5$; all $P<0.001$ ) (Table 4). The mean differences for the DA scales between the first and second assessment in the study

Table 2 Mean values of various rheumatoid arthritis core data set measures and disease activity assessment tools at baseline and at 3-month follow-up

\begin{tabular}{lcc}
\hline Variables & \multicolumn{2}{c}{ Mean \pm SD } \\
\cline { 2 - 3 } & At baseline & At 3-month follow-up \\
\hline PGA $(0-10 \mathrm{~cm})$ & $5.81 \pm 2.49$ & $4.23 \pm 2.12$ \\
EGA $(0-10 \mathrm{~cm})$ & $5.16 \pm 2.29$ & $3.88 \pm 2.02$ \\
TJC (0-28) & $12.30 \pm 8.34$ & $6.57 \pm 5.90$ \\
SJC (0-28) & $4.75 \pm 4.83$ & $3.07 \pm 3.36$ \\
ESR (0-100 mm/h) & $37.41 \pm 17.64$ & $28.04 \pm 14.88$ \\
Pain score $(0-10)$ & $5.66 \pm 2.54$ & $4.34 \pm 2.18$ \\
RADAI-5 (0-10.0) & $5.14 \pm 2.17$ & $3.76 \pm 1.92$ \\
CDAI (0-76) & $27.96 \pm 15.46$ & $17.67 \pm 12.46$ \\
DAS28-ESR & $5.58 \pm 1.55$ & $4.54 \pm 1.41$ \\
\hline
\end{tabular}

CDAI, Clinical Disease Activity Index; DAS28, Disease Activity Score 28; EGA, evaluator's global health assessment; ESR, erythrocyte sedimentation rate; PGA, patient's global health assessment; RADAI-5, Rheumatoid Arthritis Disease Activity Index-5; SJC, swollen joint counts; TJC, tender joint counts. population were as follows: $\triangle \mathrm{RADAI}-5=-1.37$; $\Delta \mathrm{DAS} 28=-1.04, \quad$ and $\Delta \mathrm{CDAI}=-10.29$. These changes were significantly intercorrelated, with a $P$ value less than 0.001 (Table 5; Figs 3, 4).

For agreement analysis, kappa was calculated. For the relationship between the RADAI-5 and DAS28, it appeared to be 0.563 at baseline and 0.411 at 3-month follow-up assessment, which can be regarded as average and significant agreement $(P<0.001)$. Kappa for the relationship of RADAI-5 with CDAI was in the same range $(0.595$ at baseline and 0.574 at 3 -month followup; all $P<0.001)$.

\section{Discussion}

$\mathrm{RA}$ is a noncurable but treatable chronic inflammatory systemic disease associated with progressive joint damage and disability, which is directly related to the duration of active disease. Consistent and frequent DA evaluation followed by consequent treatment adjustment is needed to improve outcome in patients with RA, as shown in the short-term perspective of clinical trials [3]. Various measures to assess the DA have been developed, but no single measure can reliably capture DA in all patients. This may be owing to the high variability of the presentation and course of RA as well as the reflection of different disease characteristics.

While assessing RA, most clinicians or rheumatologists focus on joints rather than functional status and pain as important measures of DA [17]. Second, they do not even perform quantitative joint counts at most visits [5]. Composite indices such as DAS28 and CDAI have been successfully used to express RA activity fluctuations [18], but as both require joint counts, which is not generally done by most rheumatologist in most patients on their every visit, thus are not suitable for daily-basis DA assessment in routine outdoors [15].

Moreover, besides DAS28 and CDAI, radiographs and other imaging modalities such as MRI and ultrasound (US) may also be appropriate to measure RA DA. The sensitivity of US is greater than that of

Table 3 Numbers of patients as per disease severity by using various assessment tools

\begin{tabular}{|c|c|c|c|c|c|c|}
\hline \multirow[t]{2}{*}{ Activity/severity } & \multicolumn{3}{|c|}{ At baseline } & \multicolumn{3}{|c|}{ 3-month follow-up } \\
\hline & RADAI-5 & DAS28 & CDAI & RADAI-5 & DAS28 & CDAI \\
\hline High & 54 & 66 & 61 & 30 & 18 & 25 \\
\hline Moderate & 25 & 24 & 23 & 53 & 44 & 46 \\
\hline Low & 14 & 6 & 13 & 8 & 26 & 25 \\
\hline Remission & 7 & 4 & 3 & 9 & 12 & 4 \\
\hline
\end{tabular}

CDAI, Clinical Disease Activity Index; DAS28, Disease Activity Score 28; RADAl-5, Rheumatoid Arthritis Disease Activity Index-5. Bold letters signify the most number of patients in both assessments. 
Figure 1

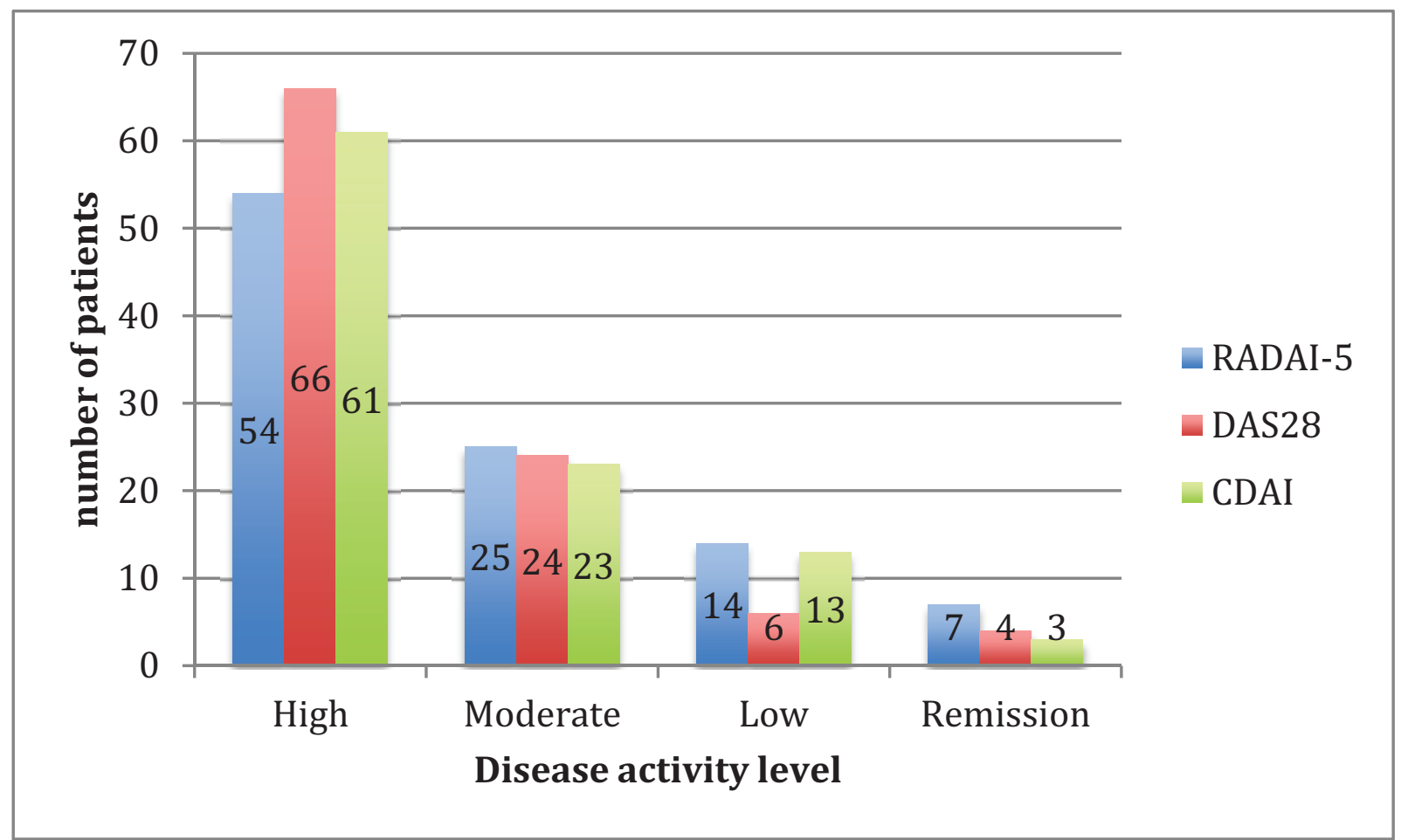

Distribution of patients according to the various assessment tools at baseline (first visit). CDAI, Clinical Disease Activity Index; DAS28, Disease Activity Score 28; RADAI-5, Rheumatoid Arthritis Disease Activity Index-5.

\section{Figure 2}

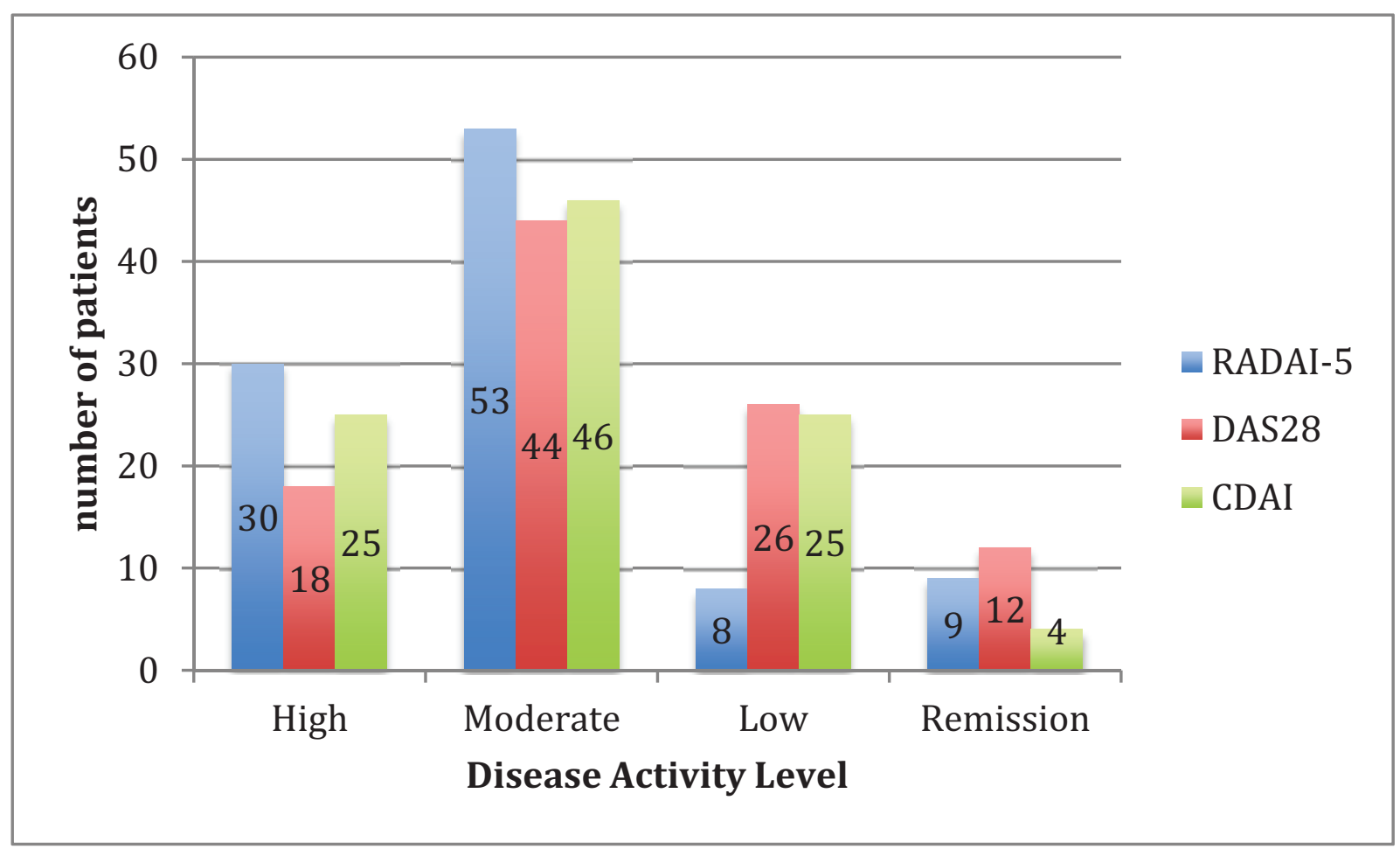

Distribution of patients according to the various assessment tools at follow up (second visit). CDAI, Clinical Disease Activity Index; DAS28, Disease Activity Score 28; RADAI-5, Rheumatoid Arthritis Disease Activity Index-5.

other imaging techniques in the early detection of aggressive arthritis and surveillance of DA [19]. US7 score is simple and practical sum scoring system for use in the detection of synovitis in patients with RA [20]. 
In addition, various trials have shown that patient selfreported measures appear more reliable (reproducible)

Table 4 Correlation of Rheumatoid Arthritis Disease Activity Index-5 with various disease activity parameters at baseline and at 3-month follow-up

\begin{tabular}{lccccc}
\hline Parameters & \multicolumn{2}{c}{ At baseline } & & \multicolumn{2}{c}{ At 3-month follow-up } \\
\cline { 2 - 3 } \cline { 5 - 6 } & Spearman's $\rho$ & $P$ value & & Spearman's $\rho$ & $P$ value \\
\hline PGA & 0.928 & $<0.001$ & & 0.969 & $<0.001$ \\
EGA & 0.925 & $<0.001$ & & 0.959 & $<0.001$ \\
TJC & 0.746 & $<0.001$ & & 0.825 & $<0.001$ \\
SJC & 0.512 & $<0.001$ & & 0.745 & $<0.001$ \\
Pain VAS & 0.934 & $<0.001$ & & 0.967 & $<0.001$ \\
CDAI & 0.856 & $<0.001$ & & 0.938 & $<0.001$ \\
DAS28 & 0.862 & $<0.001$ & & 0.942 & $<0.001$ \\
\hline
\end{tabular}

CDAI, Clinical Disease Activity Index; DAS28, Disease Activity Score 28 using erythrocyte sedimentation rate; EGA, evaluator's global health assessment; PGA, patient's global health assessment; SJC, swollen joint counts; TJC, tender joint counts; VAS, visual analog score.

Table 5 Correlation of Rheumatoid Arthritis Disease Activity Index-5 change ( $\Delta$ Rheumatoid Arthritis Disease Activity Index-5) ${ }^{\text {a }}$ with change in other activity measures

\begin{tabular}{lccc}
\hline Activity measures & Mean change \pm SD & Spearman's $\rho$ & $P$ value \\
\hline$\Delta$ DAS28 & $-1.04 \pm 1.58$ & 0.896 & $<0.001$ \\
$\Delta$ CDAl & $-10.29 \pm 15.75$ & 0.837 & $<0.001$ \\
\hline
\end{tabular}

CDAI, Clinical Disease Activity Index; DAS28, Disease Activity Score $28 .{ }^{a}-1.37 \pm 2.15 ; \Delta$ DAS28, change in DAS28 score; $\triangle \mathrm{CDAl}$ change in CDAI than joint count measures [21], and also more likely to be abnormal in patients with RA than an ESR and Creactive protein in RA [22]. Pincus and colleagues suggested that three patient measures only (i.e. physical function, pain, and global status) of the seven American College of Rheumatology core set measures are as reliable as the whole core set measures for describing RA activity changes and can constitute the basis for therapeutic decisions [7]. Moreover, patient self-administered tools such as RADAI-5 and Routine Assessment of Patient Index Data 3 appeared to be equally or even more informative than even a full joint count with respect to prognosis and monitoring of RA [6,7,23]. RADAI-5 is a physician independent and patient self-administered activity assessment tool which hardly takes $20-30 \mathrm{~s}$ in contrast to $2-3 \mathrm{~min}$ for a CDAI, and $3-5 \mathrm{~min}$ for a DAS28 and does not include any laboratory measurement and therefore all variables are easily available at point of care in the clinical setting, which can in turn produce more consistency in timing and completeness of disease measurement [8]. RADAI-5 does not include an item directly targeting physical function that is known to be a strong predictor of disability and mortality in patients with RA $[4,24]$ but in support, it comprises questions targeting patient's pain perception and global health estimate, which can be seen as surrogates for

Figure 3

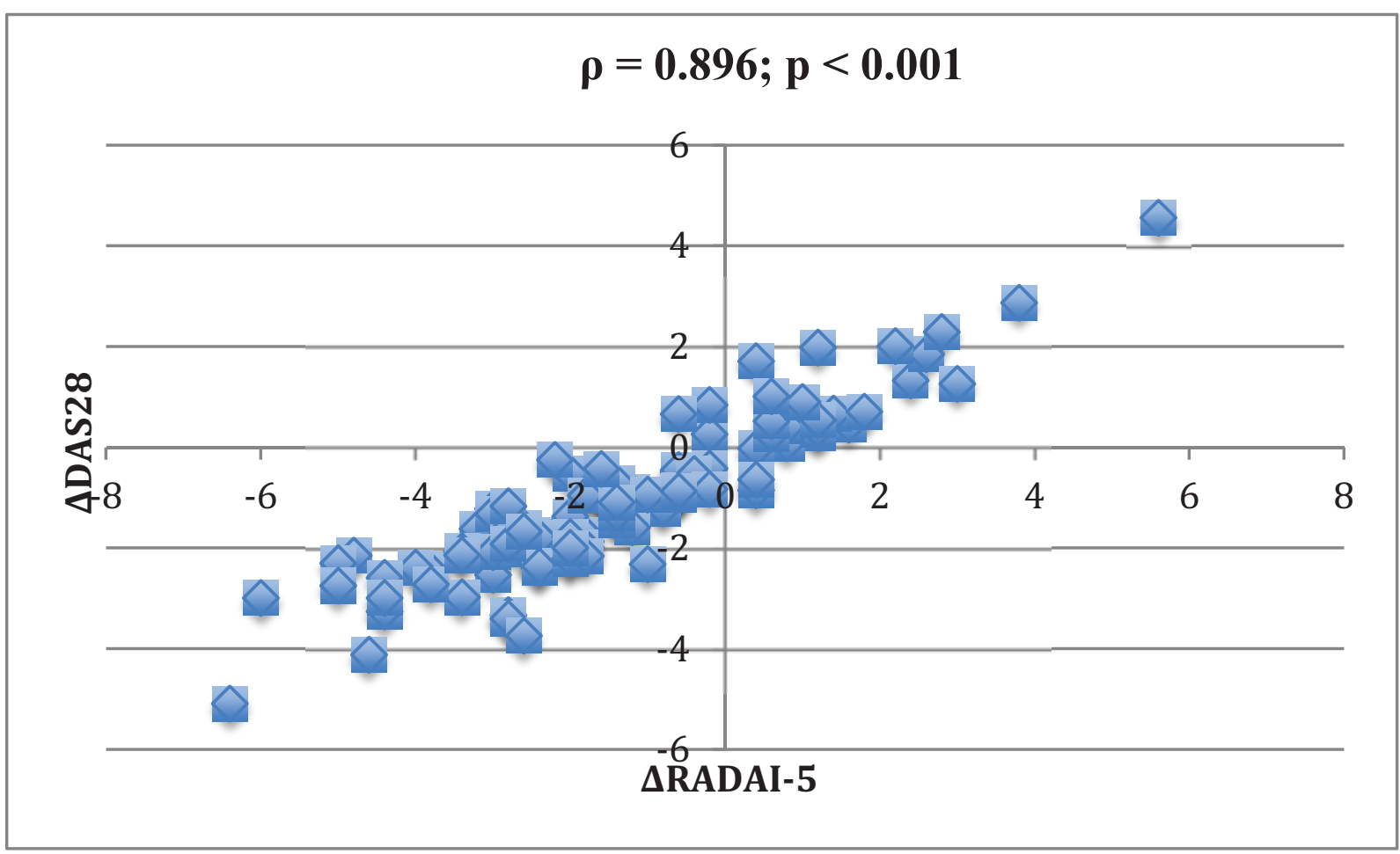

Significant correlation between change in RADAI-5 (on $x$ axis) and change in DAS28 (on $y$ axis) at follow-up visit. $\rho$, Spearman's correlation coefficient; $\triangle \mathrm{DAS} 28$, change in Disease Activity Score 28; $\triangle$ RADAI-5, change in Rheumatoid Arthritis Disease Activity Index-5. 


\section{Figure 4}

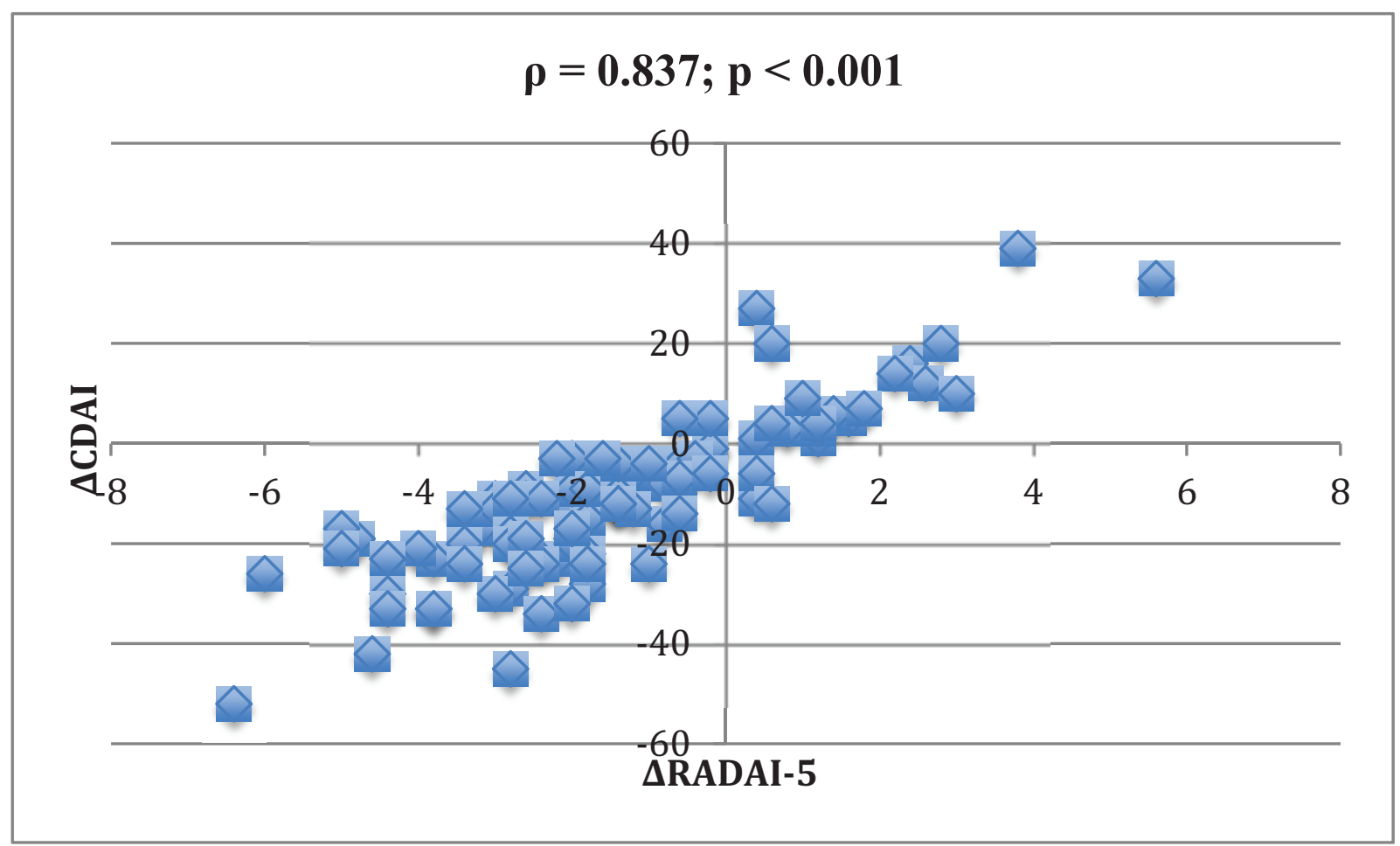

Significant correlation between change in RADAI-5 (on $x$ axis) and change in CDAI (on $y$ axis) at follow-up visit. $\rho$, Spearman's correlation coefficient; $\triangle \mathrm{CDAl}$, change in Clinical Disease Activity Index; $\triangle$ RADAI-5=change in Rheumatoid Arthritis Disease Activity Index-5.

functionality [8]. The present study was planned to assess whether RADAI-5 could be used as a valid tool for daily RA monitoring, to assess its sensitivity to improvement or flare-up of RA disease, and to compare its predictability to assess RA activity with respect to DAS28 and CDAI.

Demographic profile of our study group is almost similar to that of previous studies. Malaviya et al. [25] had studied the prevalence of RA in Northern India and showed a prevalence of RA approximately three to four times higher in females than males. In a study by Leeb et al. [8], the mean age of the patients was 57 years (higher than the mean age of our study group), and almost $80 \%$ of the patients were women (as in our study). In another study done by Rintelen et al. [26], the study group had 78\% women, and the mean duration of disease was 62 months (as in our study). In a study done by Bossert et al. [9], 200 patients were included as patients in which 154 (78\%) patients patients were RF positive (as in our study). In another study done by Rintelen et al. [26], RF positivity of the study group was $59.4 \%$.

At the first assessment, the means for the RADAI-5, DAS28, and CDAI were 5.14, 5.58, and 27.96, respectively (Table 2 ), which indicate high DA, on average, for the entire patient population. At the second assessment after 3 months, the mean for RADAI-5 was 3.76, for DAS28 was 4.54 , and for CDAI was 17.67 , indicating a moderate DA (Table 2). Thus, the aforementioned findings indicate that RADAI-5 assessment was very close to or almost similar to DAS28 and CDAI assessment.

The study population was then distributed into four groups according to the level of DA. At the first visit, most patients were found to have high DA, whereas on subsequent second visit, moderate activity was found in most patients (Table 3; Figs 1,2). This means RADAI5 assesses RA as efficiently as DAS28 and CDAI at individual activity level. However, it was also seen that RADAI-5 assessment was not similar to DAS28 and CDAI at remission and low disease activity state (Table 3; Figs 1, 2).

In the present study, RADAI-5 was correlated significantly with CDAI (at first visit $\rho=0.856$; at second visit $\rho=0.938$; all $P<0.001$ ) and DAS28 (at first visit $\rho=0.862$; at second visit $\rho=0.942$; all $P<0.001$ ). In a study done by Leeb et al. [8], $\rho$ between RADAI-5 and CDAI was 0.740 and between RADAI-5 and DAS28 was 0.638. Bossert et al. [9] also found RADAI-5 correlated with CDAI $(\rho=0.743)$ and with DAS28 $(\rho=0.662)$ significantly 
Table 6 Number of patients and their mean values for improvement and deterioration in disease activity as assessed by different assessment tools at follow-up visit

\begin{tabular}{lccrc}
\hline DA measures & \multicolumn{2}{c}{ Improvement } & \multicolumn{2}{c}{ Deterioration } \\
\cline { 2 - 3 } & Number of patients & Mean & Number of patients & Mean \\
\hline RADAI-5 & 76 & -2.31 & 24 & 1.58 \\
DAS28 & 76 & -1.73 & 24 & 1.16 \\
CDAI & 77 & -16.65 & 23 & 11.00 \\
\hline
\end{tabular}

CDAI, Clinical Disease Activity Index; DAS28, Disease Activity Score 28 using erythrocyte sedimentation rate; RADAI-5, Rheumatoid Arthritis Disease Activity Index-5.

Figure 5

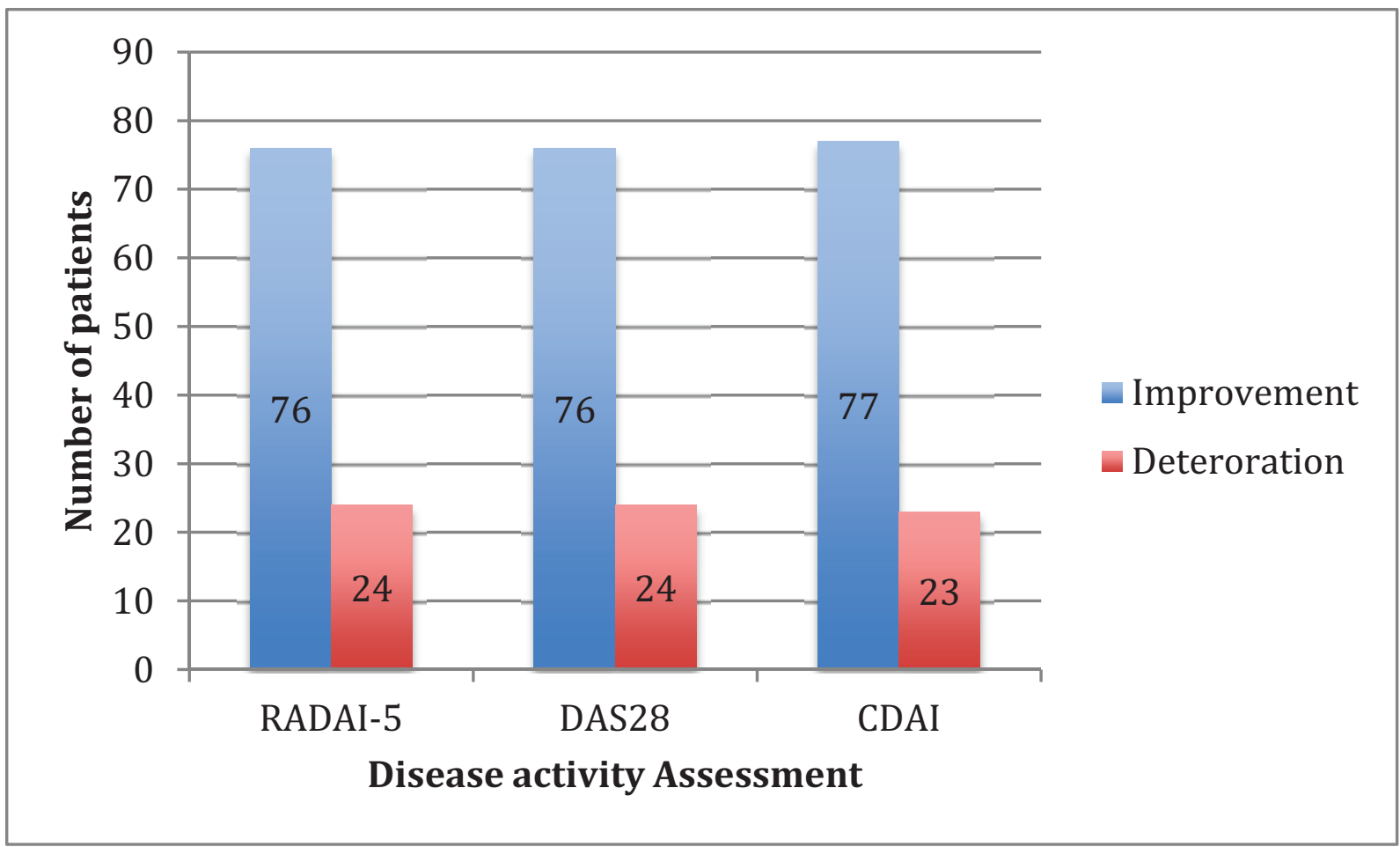

Distribution of patients according to the improvement and deterioration in RA disease as assessed by various scales at follow-up (second visit). $\mathrm{CDAl}=$ Clinical Disease Activity Index; DAS28, Disease Activity Score 28; RA, rheumatoid arthritis; RADAI-5, Rheumatoid Arthritis Disease Activity Index-5.

$(P<0.01)$ in their study. In another study by Sunar et al. [10], RADAI-5 was correlated with DAS28, with $r=0.81 ; P$ value less than 0.001 . In an Egyptian study, correlation between RADAI-5 and DAS28 was also significant $(r=0.90 ; P<0.001)[11]$.

At the second assessment, mean RADAI-5, mean CDAI, and mean DAS28 changed by -1.37 , -10.29 , and -1.04 , respectively. All these values indicate improvement in DA, which may be owing to that patients were taking treatment. The change in RADAI-5 score ( $\triangle$ RADAI-5) was significantly correlated with change in DAS28 ( $\triangle \mathrm{DAS} 28)$ ( $\rho=0.896 ; \quad P<0.001)$, as well as with change in CDAI ( $\triangle$ CDAI) $(\rho=0.837 ; P<0.001)$ (Table 5; Figs 3 , 4). Leeb et al. [8] also found a strong positive correlation for RADAI-5 change with respect to change in DAS28 $(\rho=0.589 ; P<0.001)$ and CDAI $(\rho=0.569 ; P<0.001)$ in their study.

Reduction in DA at second visit was considered as improvement and flare-up of DA at second visit considered as deterioration. Improvement was noted in total 76 patients, whereas deterioration was noted in 24 patients when assessed by using RADAI- 5 and DAS28-ESR (Table 6). Almost similar results were found when assessment was done by using CDAI (77 improved, 23 deteriorated) (Table 6). This means RADAI-5 is as sensitive as DAS28-ESR and CDAI for assessing any change in DA (Fig. 5).

On agreement analysis between two measures, we found an average although statistically significant agreement between RADAI-5 and DAS28 (kappa 
0.563 at first visit; 0.411 at second visit) and CDAI (kappa 0.595 at first visit; 0.574 at second visit). In a study by Leeb et al. [8], kappa between RADAI-5 and DAS28 was 0.290 and kappa between RADAI-5 and DAS28 was 0.369 , suggestive of a fair but statistically significant agreement. In another study done by Rintelen et al. [26], RADAI-5 had a fair relationship with DAS28 (kappa 0.236; $P<0.001$ ) and CDAI (kappa 0.280; $P<0.001$ ).

However, the limitations of our study include the following: first, the study was performed in a single center within a relatively small region; second, the study group, although representative of the center's entire RA patient population, in general had moderate to severe DA; third, fibromyalgia that coexists in 15-20\% of patients with RA could have exerted an influence on RADAI-5 [27]; and fourth, increased self-efficacy as member of study group constitutes a factor possibly influencing a patient's self-assessment [28].

The observations of our study are in well consonance with the previous studies, which favors the use of RADAI-5 for routine clinical settings as well as home-based settings. It is also suggested that RADAI-5 has a high reliability, high acceptability, good feasibility, and high sensitivity for assessment of any improvement or deterioration in RA DA.

\section{Conclusion}

In our study, RADAI- 5 is found to be compatible with physician-derived tools, which are developed mainly for research purposes, and seems a valid instrument for measuring and monitoring of RA DA and hence is capable of substituting the use of other tools in routine patient care.

\section{Financial support and sponsorship Nil.}

\section{Conflicts of interest}

There are no conflicts of interest.

\section{References}

1 Bichile L. Clinical features and organ involvement in RA. In: Rao URK, Mahendranath KM, Misra R, Gupta SJ, Handa R, Chaturvedi V, eds. Manual of rheumatology. 4th ed. Indian Rheumatology Association; 2014. 176-184.

2 Shah A, Clair EW. Rheumatoid arthritis. In: Longo DL, Fauci AS, Kasper DL, Hauser SL, Jameson JL, Loscalzo J, eds. 18th ed. Harrison's principles internal medicine. New York: McGrawHill; 2011. 2738-2752.

3 Grigor C, Capell H, Stirling A. Effect of a treatment strategy of tight control for rheumatoid arthritis (the TICORA study): a single-blind randomised controlled trial. Lancet 2004; 364:263-269.
4 Pincus T, Sokka T. Quantitative clinical assessment in busy rheumatology settings: the value of short patient questionnaires. J Rheumatol 2008; 35:1235-1237.

5 Pincus T, Segurado OG. Most visits of most patients with rheumatoid arthritis to most rheumatologists do not include a formal quantitative joint count. Ann Rheum Dis 2006; 65:820-822.

6 Pincus T, Amara I, Segurado OG, Bergman M, Koch GG. Relative efficiencies of physician/assessor global estimates and patient questionnaire measures are similar to or greater than joint counts to distinguish adalimumab from control treatments in rheumatoid arthritis clinical trials. J Rheumatol 2008; 35:201-205.

7 Pincus T, Strand V, Koch G, Amara I, Crawford B, Wolfe F, et al. An index of the three core data set patient questionnaire measures distinguishes efficacy of active treatment from that of placebo as effectively as the American College of Rheumatology 20\% response criteria (ACR20) or the Disease Activity Score (DAS) in a rheumatoid arthritis clinical trial. Arthritis Rheum 2003; 48:625-630.

8 Leeb BF, Haindl PM, Maktari A, Nothnagl T, Rintelen B. Patient centered rheumatoid arthritis disease activity assessment by a modified RADAI. J Rheumatol 2008; 35:1294-1299.

9 Bossert M, Prati C, Vidal C, Bongain S, Toussirot E, Wendling D. Evaluation of self-report questionnaires for assessing rheumatoid arthritis activity: a cross-sectional study of RAPID3 and RADAI5 and are detection in 200 patients. Joint Bone Spine 2012; 79:57-62.

10 Sunar I, Garip Y, Yilmaz O, Bodur H, Ataman S. Disease Activity (Rheumatoid Arthritis Disease Activity Index-5) in patients with rheumatoid arthritis and its association with quality of life.Pain, fatigue, and functional and psychological status. Arch Rheumatol 2015; 30:144-149.

11 Kamel SR. Using Rheumatoid Arthritis Disease Activity Index-5 questionnaire in the assessment of disease activity in patients with rheumatoid arthritis: correlation with quality of life, pain, and functional status. Egypt Rheumatol Rehabil 2018; 45:43-48.

12 Arnett FC, Edworthy SM, Bloch DA, Mcshane DJ, Fries JF, Cooper NS, et al. The American Rheumatism Association 1987 revised criteria for the classification of rheumatoid arthritis. Arthritis Rheum 1988; 31:315-324.

13 Van Gestel AM, Haagsma CJ, Van Riel PL. Validation of rheumatoid arthritis improvement criteria that include simplified joint counts. Arthritis Rheum 1998; 41:1845-1850.

14 Aletaha D, Nell VP, Stamm T, Uffmann M, Pflugbeil S, Machold K, et al. Acute phase reactants add little to composite disease activity indices for rheumatoid arthritis: validation of a clinical activity score. Arthritis Res Ther 2005; 7:R796-R806.

15 Fransen J, Creemers MC, Van Riel PL. Remission in rheumatoid arthritis: agreement of the disease activity score (DAS28) with the ARA preliminary remission criteria. Rheumatology (Oxford) 2004; 43:1252-1255.

16 Aletaha D, Smolen J. The Simplified Disease Activity Index (SDAI) and the Clinical Disease Activity Index (CDAI): a review of their usefulness and validity in rheumatoid arthritis. Clin Exp Rheumatol 2005; 23:S100-S108.

17 Leeb BF, Haindl PM, Maktari A, Nothnagl T, Rintelen B. DAS28 values differ considerably depending on patient's pain perception and gender. $J$ Rheumatol 2007; 34:2382-2387.

18 Prevoo ML, van't Hof MA, Kuper HH, van Leeuwen MA, van de putte LB, van Riel PL. Modified disease activity scores that include twenty-eight-joint counts. Development and validation in a prospective longitudinal study of patients with rheumatoid arthritis. Arthritis Rheum 1995; 38:44-48.

19 Østergaard M, Szkudlarek M. Ultrasonography a valid method for assessing rheumatoid arthritis. Arthritis Rheum 2005; 52:681-686.

20 Kamel SR, Sadek HA, Mohamed FA, Abu Samra MF, Osman HM. The ultrasound 7 score in the assessment of synovitis in rheumatoid arthritis: correlation with clinical disease activity indices. Egypt Rheumatol Rehabil 2017; 44:103-110.

21 Kvien TK, Mowinckel P, Heiberg T, Dammann KL, Aanerud GJ, Alme TN, et al. Performance of health status measures with a pen based personal digital assistant. Ann Rheum Dis 2005; 64:1480-1484.

22 Wolfe F, Michaud K. The clinical and research significance of the erythrocyte sedimentation rate. J Rheumatol 1994; 21:1227-1237.

23 Wong AL, Wong WK, Harker J, Sterz M, Bulpitt K, Park G, et al. Patient selfreport tender an swollen joint counts in early rheumatoid arthritis. Western Consortium of Practicing Rheumatologists. J Rheumatol 1999; 26:2551-2561.

24 Pincus T, Keysor J, Sokka T, Krishnan E, Callahan LF. Patient questionnaires and formal education level as prospective predictors of mortality over 10 years in $97 \%$ of 1416 patients with rheumatoid arthritis from 15 United States private practices. J Rheumatol 2004; 31:229-234. 
25 Malaviya AN, Kapoor SK, Singh RR, Kumar A, Pande I. Prevalence of rheumatoid arthritis in the adult Indian population. Rheumatol Int 1993; 13:131-134.

26 Rintelen B, Haindl PM, Sautner J, Leeb BA, Deutsch C, Leeb BF. The Rheumatoid Arthritis Disease Activity Index-5 in daily use: proposal for disease activity Categories. J Rheumatol 2009; 36:918-924.
27 Leeb BF, Andel I, Sautner J, Nothnagl T, Rintelen B. The DAS28 in rheumatoid arthritis and fibromyalgia patients. Rheumatology (Oxford) 2004; 43:1504-1507.

28 Taal E, Raskar JJ, Seydel ER, Wiegman O. Health status, adherence with health recommendations, self efficacy and social support in patients with rheumatoid arthritis. Patient Educ Couns 1993; 20:63-76. 